J. Lake Sci.(湖泊科学), 2008, 20(5): 591-599

http://www.jlakes.org. E-mail: jlakes@niglas.ac.cn

(C)2008 by Journal of Lake Sciences

\title{
藏南普莫雍错流域水体离子组成与空间分布及其环境意义
}

\author{
鞠建廷 ${ }^{1,3}$, 朱立平 ${ }^{2}$, 汪 勇 $^{2}$, 谢曼平 ${ }^{2}$, 彭 平 ${ }^{2}$, 甄晓林 ${ }^{2}$, 王君波 ${ }^{2}$ \\ (1: 中国科学院地理科学与资源研究所, 北京 100101) \\ (2: 中国科学院青藏高原研究所, 北京 100085) \\ (3: 《中国科学》杂志社, 北京 100717)
}

摘 要: 对藏南普莫雍错湖水及其周围人湖河流水体进行了离子化学成分分析, 对部分湖泊和河流水样作氧同位素分析. 结 果显示, 不同人湖河流离子组成与湖水本身离子组成有较大差异. 湖水的主要离子组合是 $\mathrm{Mg}^{2+}-\mathrm{Ca}^{2+}-\mathrm{HCO}_{3}{ }^{-}-\mathrm{SO}_{4}{ }^{2-}$, 而主要补 给河流加曲为 $\mathrm{Ca}^{2+}-\mathrm{Mg}^{2+}-\mathrm{HCO}_{3}{ }^{-}$. 加曲人湖河口 $2 \mathrm{~m}$ 水深以内水化学性质差异大, 湖泊其他地区差异小. 加曲对河口三角洲之 上湖水影响显著. 其他河流对河口处湖水影响较小. Gibbs 图显示湖水离子的组成主要与流域内的岩石风化有关. 离子比例和 三角图分析说明控制人湖河水离子主要过程是碳酸盐、黄铁矿和硅酸盐风化. 湖泊与河流水体离子的组成差异较大, 原因可 能是蒸发浓缩导致的 $\mathrm{CaCO}_{3}$ 的沉淀. 其结果有助于正确理解湖泊沉积碳酸盐的环境指示意义.

关键词: 普莫雍错; 主要离子; 氧同位素; 空间分布; 沉积过程

\section{Composition, spatial distribution and environmental significance of water ions in Lake Pumayum Co and its catchment, Southern Tibet}

\author{
JU Jianting ${ }^{1,3}$, ZHU Liping ${ }^{2}$, WANG Yong ${ }^{2}$, XIE Manping ${ }^{2}$, PENG Ping ${ }^{2}$, ZHEN Xiaolin ${ }^{2}$ \& WANG Junbo ${ }^{2}$ \\ (1: Institute of Geographical Sciences and Natural Resources Research, Chinese Academy of Sciences, Beijing 100101, P.R.China) \\ (2: Institute of Tibetan Plateau Research, Chinese Academy of Sciences, Beijing 100085, P.R.China) \\ (3: Science in China Press, Beijing 100717, P.R.China)
}

Abstract: The chemistry of major cations $\left(\mathrm{Mg}^{2+}, \mathrm{Ca}^{2+}, \mathrm{Na}^{+}\right.$and $\left.\mathrm{K}^{+}\right)$and anions $\left(\mathrm{HCO}_{3}^{-}, \mathrm{SO}_{4}{ }^{2-}\right.$ and $\left.\mathrm{Cl}^{-}\right)$in the water of Lake Pumayum $\mathrm{Co}$ and of its inflow river were studied, and the results revealed the obvious ionic difference among various inflow rivers and the lake. The chemical type of the lake water was $\mathrm{Mg}^{2+}-\mathrm{Ca}^{2+}-\mathrm{HCO}_{3}{ }^{-}-\mathrm{SO}_{4}{ }^{2-}$, and the major ions of the main inflow river were $\mathrm{Ca}{ }^{2+}$ $-\mathrm{Mg}^{2+}-\mathrm{HCO}_{3}{ }^{-}$. In the lake inlet within the depth less than $2 \mathrm{~m}$ of Jiaqu River, the main inflow river, there was significant variance of water chemistry. However, it was almost same at other area of the lake. Jiaqu River had a distinct effect on the chemistry of the water on the estuary delta, whereas other rivers have minor effect on the water on estuary. The Gibbs plot revealed that chemical compositions of the lake water was correlative with rock weathering in the drainage area. Ion ratio and ternary plots further explored the main processes controlling the water chemistry of the catchment were carbonate weathering, pyrite weathering and silicate weathering. The different water chemical characteristics between river water and lake water may result from the $\mathrm{CaCO}_{3}$ precipitation. The outcome will benefit comprehending the environmental significance of carbonate in lacustrine sediment.

Keywords: Lake Pumayum Co; major ion chemistry; oxygen isotope; spatial distribution; sedimentary process

青藏高原的湖泊大部分是内流湖，反映湖泊本身以及气候环境变化的各种环境指标能够最大限度地

* 国家自然科学基金项目(40571172, 40331006)、国家重点基础研究发展规划项目(2005CB422002)和中国科学院知识创新 工程方向性项目(KZCX3-SW-339)联合资助. 2007-07-26 收稿; 2007-10-15 收修改稿. 鞠建廷, 男, 1977 年生, 博士; E-mail: jujt@scichina.org. 
保留在湖泊沉积物以及湖盆流域内，有利于开展过去不同时间尺度气候环境变化历史、阶段水热组合和 古生态特征研究 ${ }^{[1]}$. 湖泊沉积物中反映环境变化的物理、化学和生物指标与湖泊水化学条件密切相关 ${ }^{[2]}$. 对一个地表径流和降水补给为主的湖泊来说, 其水化学性质受流域盆地的构造活动和岩石风化 ${ }^{[3-4]}$ 、气候 变化 ${ }^{[5]}$ 以及人类活动 ${ }^{[2]}$ 的影响 ${ }^{[6]}$. 水体离子组成是水化学性质的重要方面, 因此在一个湖泊流域内研究河 流与湖泊水体化学离子特征, 对于理解河流对湖泊的补给关系、湖水的离子组成和来源具有重要意义. 尽管已有许多研究 ${ }^{[7-10]}$ 利用湖泊沉积物的元素成分作为过去环境变化的指标, 但大部分在西藏地区开展 的相似工作都是基于其他地区的结果而加以应用. 由于湖泊沉积存在较大的区域差异，在西藏地区开展 湖泊的水化学离子变化研究, 对于理解湖泊沉积物的来源以及沉积物在空间上反映环境变化的程度具有 重要作用, 有助于湖泊现代沉积过程的研究.

本研究选择的普莫雍错湖泊位于西藏南部. 对该区的湖泊研究, 无论是从环境变化角度还是其他方 面, 都是相对薄弱的. 本文重点讨论普莫雍错湖泊及其人湖河流的水化学特征、主要离子来源及成因. 通 过分析可以为湖泊的沉积过程研究提供一些基础的研究资料.

\section{1 区域概况}

普莫雍错 $\left(90^{\circ} 13^{\prime}-90^{\circ} 33^{\prime} \mathrm{E}, 28^{\circ} 30^{\prime}-28^{\circ} 38^{\prime} \mathrm{N} ; 2004\right.$ 年测得湖面海拔 $\left.5030 \mathrm{~m}\right)$ 位于羊卓雍错以南, 喜马拉 雅山北坡一个山间盆地内. 湖面面积 $290.0 \mathrm{~km}^{2}$, 集水面积 $1232.9 \mathrm{~km}^{2}$, 补给系数为 4.2 , 发育系数 $1.56^{[2]}$. 注人普莫雍错的主要河流有 4 条(图 1), 其中从西岸注人的加曲河流最大，占全部人湖总流量的 $77 \%$ 左 右 ${ }^{[1]}$. 湖区属藏南山地灌丛草原半干旱气候, 年均温 $2-4^{\circ} \mathrm{C}$, 年降水量 $300 \mathrm{~mm}$ 左右 ${ }^{[2]}$.

湖泊的东南部有一条经人工改造过的出湖河流, 高湖面时湖水经此河流人卡洞加曲注人羊卓雍错. 加曲源头有大量的现代冰川和一些面积不等的冰川湖分布，冰雪融水径流较丰. 本研究调查表明，湖泊 西侧加曲河口处有一水下三角洲. 水深 2.6-2.7m 处, 水色发生明显变化, 由类似加曲河水的浑浊转为微 浑的浅绿色. 水深 3.5-8m 处的陡坡是河口三角洲的前缘.

在地层分区上，本区位于喜马拉雅北区，拉轨岗日分区，上三叠统涅如群 $\left(\mathrm{T}_{3} \mathrm{ny}\right)$. 上部是硅质砂岩、 细沙岩、长石石英砂岩和深灰色板岩, 常夹硅质岩、灰岩, 板岩含菱铁质和砂质结核及黄铁矿细粒, 厚度 $3750 \mathrm{~m}$. 下部以深灰色页岩为主, 含砂质结核, 厚 $320 \mathrm{~m}^{[11]}$. 受第四纪冰川活动影响, 冰碛物广布在山谷中,

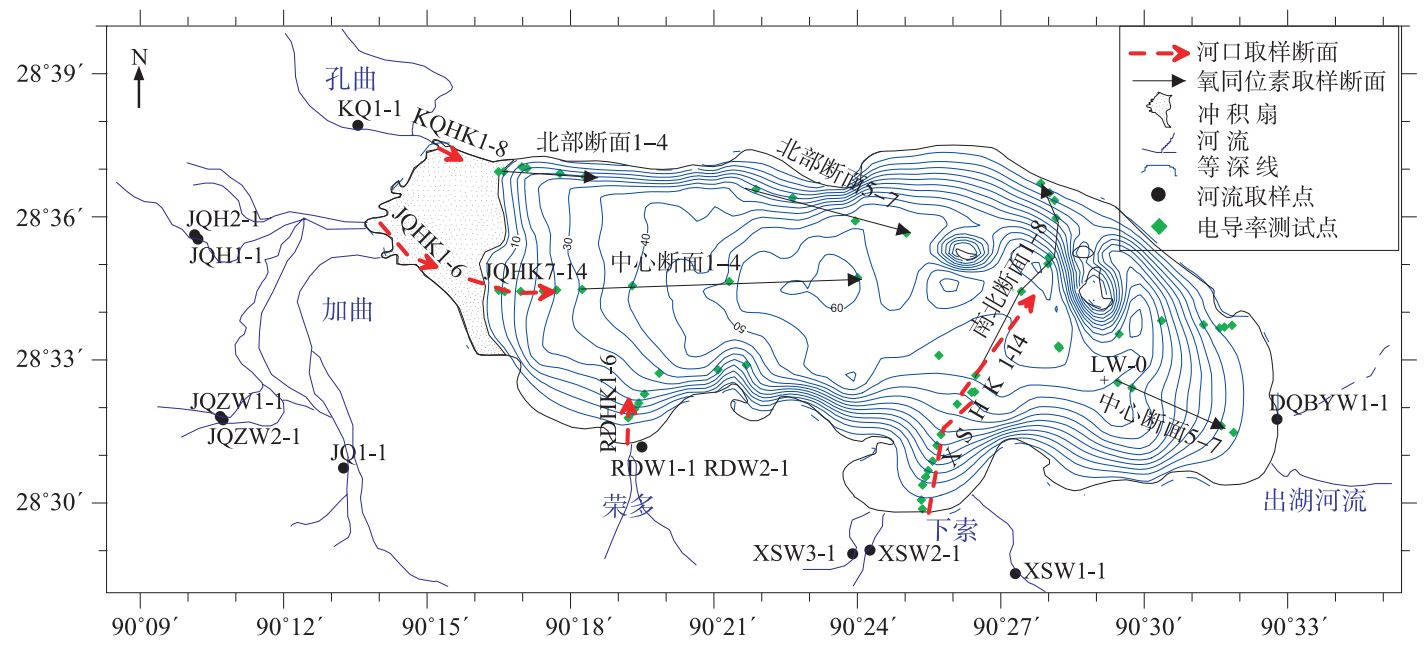

图 1 普莫雍错等深线与采样示意(加曲河口(JQHK)、孔曲河口 $(K Q H K) 、$ 荣多河口(RDHK)、下索河口

(XSHK)样品 1、2、3 代表各河流人湖口到湖泊内部的水样)

Fig.1 Bathymetric map of Lake Pumayum Co and sampling sites Numbers of JQHK, KQHK, RDHK, XSHK indicate the samples from each river mouth to the inner lake respectively 
从山麓地带到湖岸可见第四纪松散堆积物 ${ }^{[12]}$. 冲积平原分布在东部、南部和西部湖岸, 北部湖岸紧邻 山脚.

\section{2 取样和分析方法}

用于水化学分析的水样分两部分进行采集(图 1): 一部分采自包括小溪流在内的所有人湖河流, 共取 样 12 个; 一部分根据等深线分布采自普莫雍错河流人湖口垂直等深线向湖心的不同位置, 共取表层水样 45 个. 用 HYDROLAB DS5 在湖内 58 个点现场测试表层水电导率、 $\mathrm{pH}$ 等(图 1). 并在湖泊内部按 3 条断 面取表层水样共 22 个, 对这些水样和加曲水样做氧同位素测试(图 1).

除 $\mathrm{HCO}_{3}{ }^{-}$和 $\mathrm{CO}_{3}{ }^{2}$ 外，水样其他主要阴离子用 Dionex 的 ICS-2500 离子色谱系统检测，主要阳离子用 Dionex 的 ICS-2000 离子色谱系统检测, 回收率为 98\%-102\%, 标准偏差为 $2 \%$. 对 58 个表层湖水电导率 按 HYDROLAB 提供的 0.64 的系数换算为 TDS. 所有样品的 $\mathrm{HCO}_{3}$ 浓度用离子平衡法估算. 选取部分样 品用滴定法未检测到 $\mathrm{CO}_{3}{ }^{2-}$. 氧同位素测试用 MAT253 型同位素比例质谱仪(IRMS)完成，外精度为 $0.2 \%$.

\section{3 结果与分析}

\section{1 水化学主要离子组成和 TDS}

普莫雍错主要湖区表层水的组成离子是 $\mathrm{Mg}^{2+}, \mathrm{Ca}^{2+}, \mathrm{HCO}_{3}{ }^{-}, \mathrm{SO}_{4}{ }^{2-}$. 在阳离子中, $\mathrm{Mg}^{2+}$ 和 $\mathrm{Ca}^{2+}$ 占全部阳 离子的 $80 \%$ 左右, 其中前者占阳离子的 $53 \%$ 左右, 是最大优势阳离子. 阴离子中, $\mathrm{HCO}_{3}{ }^{-}$是最主要阴离子, 占阴离子总量的 $73 \%$ 左右, $\mathrm{SO}_{4}{ }^{2-}$ 是第二优势阴离子，占阴离子总量的 $25 \%$ 左右(表 1). 因此湖水的主要离 子是 $\mathrm{Mg}^{2+}-\mathrm{Ca}^{2+}-\mathrm{HCO}_{3}{ }^{-}-\mathrm{SO}_{4}{ }^{2-}$. 这与在 1974 年 8 月获取的普莫雍错水样水化学组成 ${ }^{[13]}$ 一致. TDS 值的范围 是 $251-307 \mathrm{mg} / \mathrm{L}$.

西部水下三角洲区域水离子组成与其他湖区相比有较大差异(表 1): 虽然 $\mathrm{Ca}^{2+}$ 和 $\mathrm{Mg}^{2+}$ 也占阳离子总 量的 $85 \%$ 左右, 但是最大优势阳离子是 $\mathrm{Ca}^{2+}$, 占 $60 \%$ 左右; $\mathrm{HCO}_{3}$-数量在阴离子组成中仍然最多, 但是 $\mathrm{SO}_{4}{ }^{2-}$ 相比其它湖区含量有所增加, 占 $37 \%$ 左右. TDS 数值变化较大, 在加曲人湖口处(编号为 JQHK 的几 个样品)不到 $100 \mathrm{mg} / \mathrm{L}$; 孔曲人河口处相对较大，在 $100 \mathrm{mg} / \mathrm{L}$ 以上.

由人湖河流水化学分析可知, 河流的 TDS 差别非常大. 流量和流速最大的加曲 TDS 只有 $54.22 \mathrm{mg} / \mathrm{L}$ (样品为 JQ1-1), 而西侧冲积扇上的两条非常小的溪流 TDS 高达 $540 \mathrm{mg} / \mathrm{L}$ 以上(样品为 JQH1-1, $\mathrm{JQH} 2-1$ ), 东南侧季节性人湖小溪流 TDS 更是高达 $667 \mathrm{mg} / \mathrm{L}$ (样品为 DQBYW1-1). 其他河流 TDS 多在 100-300mg/L 之间. 然而各条河流也表现出其共性: 阳离子中主要组成是 $\mathrm{Ca}^{2+}$ 和 $\mathrm{Mg}^{2+}$, 而且 $\mathrm{Ca}^{2+}$ 含量是 $\mathrm{Mg}^{2+}$ 含量的两倍甚至更多; $\mathrm{HCO}_{3}{ }^{-}$含量占阴离子总量的 $90 \%$ 以上, $\mathrm{SO}_{4}{ }^{2-}$ 含量相对湖泊水都较低. 在离子组 成上，一些小河的阳离子与其他河流相比有其独特性. 如前面提到的东岸和西岸共三条小河, $\mathrm{Ca}^{2+}$ 含量超 过 $\mathrm{Mg}^{2+}$ ，其中西侧两条小河 $\mathrm{Na}^{+}$含量相对较高，在阳离子中含量超过 $20 \%$.

表 1 普莫雍错主要离子的当量浓度含量 $(\%)$ 及 $\mathrm{TDS}(\mathrm{mg} / \mathrm{L})$

$\left(\mathrm{TZ}^{+}\right.$和 $\mathrm{TZ}$ 分别为总阳离子和总阴离子当量浓度; 1 为开阔湖区, 2 为西部冲积扇湖区)

Tab.1 Ion composition and TDS for water samples from the broad lake area of Lake Pumayum Co $\left(\mathrm{TZ}^{+}\right.$and $\mathrm{TZ}^{-}$stand for total cations and total anions respectively; Site 1 and 2 refer to the broad lake area and the western alluvial fan of Lake Pumayum Co)

\begin{tabular}{|c|c|c|c|c|c|c|c|c|c|c|c|c|c|c|}
\hline \multirow[b]{2}{*}{ 位置 } & \multicolumn{2}{|c|}{$\mathrm{Ca}^{2+} / \mathrm{TZ}^{+}$} & \multicolumn{2}{|c|}{$\mathrm{Mg}^{2+} / \mathrm{TZ}^{+}$} & \multicolumn{2}{|c|}{$\left(\mathrm{Ca}^{2+}+\mathrm{Mg}^{2+}\right) / \mathrm{TZ}^{+}$} & \multicolumn{2}{|c|}{$\mathrm{HCO}_{3}^{-} / \mathrm{TZ}^{-}$} & \multicolumn{2}{|c|}{$\mathrm{SO}_{4}^{2-} / \mathrm{TZ}^{-}$} & \multicolumn{2}{|c|}{$\left(\mathrm{Na}^{+}+\mathrm{K}^{+}\right) / \mathrm{TZ}^{+}$} & \multicolumn{2}{|c|}{ TDS } \\
\hline & 1 & 2 & 1 & 2 & 1 & 2 & 1 & 2 & 1 & 2 & 1 & 2 & 1 & 2 \\
\hline 平均 & 25.99 & 60.31 & 53.23 & 25.66 & 79.23 & 85.96 & 72.67 & 61.11 & 25.94 & 36.79 & 20.45 & 13.90 & 285.60 & 127.52 \\
\hline 最小值 & 24.83 & 32.03 & 49.11 & 16.12 & 77.09 & 74.33 & 69.74 & 27.25 & 22.26 & 23.72 & 18.71 & 7.67 & 266.14 & 48.17 \\
\hline 最大值 & 29.55 & 74.85 & 54.71 & 48.52 & 81.16 & 92.33 & 76.71 & 75.31 & 29.45 & 64.01 & 22.63 & 25.52 & 307.61 & 264.40 \\
\hline 样品数 & 29 & 16 & 29 & 16 & 29 & 16 & 29 & 16 & 29 & 16 & 29 & 16 & 29 & 16 \\
\hline
\end{tabular}




\section{2 普莫雍错湖区水化学离子来源的 Gibbs 图分析}

研究影响地表水化学离子的主要来源, 通常使用 $\mathrm{Gibbs}^{[14]}$ 的半对数坐标图解进行分析(图 2). 纵坐标

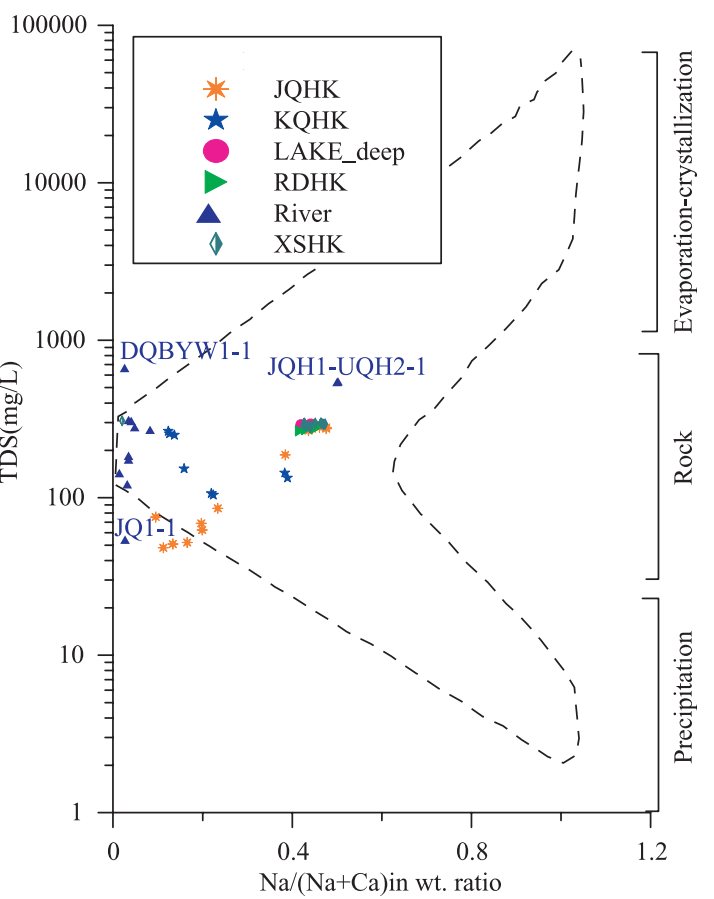

图 2 普莫雍错流域水离子在 Gibbs 图上的分布

Fig.2 Plot of TDS versus weight ratio of $\mathrm{Na}^{+} /\left(\mathrm{Na}^{+}+\mathrm{Ca}^{2+}\right)$ of Lake Pumayum Co and inflow rivers water samples(after Gibbs $\left.1970^{[14]}\right)$. Note that the major ion chemistry of the catchment distributed in the rock-dominant field 以对数表示 TDS, 横坐标以算术值表示质量 浓度比阳离子 $\mathrm{Na}^{+} /\left(\mathrm{Na}^{+}+\mathrm{Ca}^{2+}\right)$ 或阴离子 $\mathrm{Cl}^{-} /\left(\mathrm{Cl}^{-}+\mathrm{HCO}_{3}{ }^{-}\right)$的比值. 全球所有地表水的 离子组分值几乎全部落在图中的虚框.

由于普莫雍错流域河流水化学 $\mathrm{Cl}^{-}$含量 太低, 在阴离子含量中不到 0.1 个百分点(表 1), 仪器几乎检测不出, 因此 Gibbs 图的横坐 标选择用 $\mathrm{Na}^{+} /\left(\mathrm{Na}^{+}+\mathrm{Ca}^{2+}\right)$. 总体上看, Gibbs 图显示岩石的风化作用对该区水化学离子组 成的影响显著. 另外, 不同人湖河流以及河 口和湖区中心具有一定差异.

加曲(JQ1-1)和加曲河口(JQHK)水样点 都位于纵坐标 TDS 的低值区. 由于高 $\mathrm{Ca}^{2+}$ 含量, 加曲河口(JQHK) 和孔曲河口(KQHK) 浅水区水样(深度小于 $2 \mathrm{~m}$ ) 以及包括加曲 (JQ1-1)在内的多数河流水样(River)位于横 坐标的低值区. 加曲是该湖最大的人湖河流, 由于其较高的流速, 河水注人湖泊后能够在 相当一片浅水区域中产生影响, 使得河口湖 区的水化学成分 $(J Q H K)$ 与河流(JQ1-1)相近.

荣多河口、下索河口与湖区深水位置表 层样品(Lake_deep)的值聚集在一起, 由于 $\mathrm{Ca}^{2+}$ 在阳离子的含量退居其次, 因而横坐标 数值都偏高. 从河流对湖泊的影响来看, 荣 多和下索两个小流域的河流因为其流速太小

对河口处湖水影响不明显, 使得河口处与深水区湖水呈现相同的性质. 东侧一条季节性河流(样品为 DQBYW1-1)和西侧的冲积扇两条小溪流(样品为 JQH1-1, JQH2-1)位居 Gibbs 图的较高位置, 说明其 TDS 大. 该区河流 TDS 的巨大差异与慕士塔格冰川区 ${ }^{[15]}$ 和唐古拉山冰川区 ${ }^{[16]}$ 水化学分析研究结论一致: 流速 增大, 水体与河床接触时间相对较短, 土壤及岩石中可溶盐溶于水中的也相对较少; 流量增大, 冰雪融 水对可溶盐含量的稀释作用加强, 均导致了离子含量的降低.

\section{3 岩石风化对流域水化学组成的影响}

陆地水溶解盐的三种可能来源是: 大气携带的海盐(循环盐)成分; 陆地可溶性岩石(硅酸盐、碳酸盐、 蒸发盐和硫化物矿物)成分和人类输入 ${ }^{[17]}$. 本区人烟稀少，人为影响可以忽略.

Gibbs 图已经说明影响本区地表水水化学性质的主要过程是岩石的风化, 没有样点落在降水控制区. 从 $\mathrm{Na}^{+} 、 \mathrm{~K}^{+}$和 $\mathrm{Cl}^{-}$比值角度进一步分析, 海水气溶胶中 $\mathrm{Na}^{+} / \mathrm{Cl}^{-}, \mathrm{K}^{+} / \mathrm{Cl}^{-}$摩尔比分别为 0.8517 和 $0.0176^{[18]}$, 而 普莫雍错流域水体样品中 $\mathrm{Cl}^{-}$占阴离子总含量不到 $0.1 \%$ (表 1, 表 2, 图 3), $\mathrm{Na}^{+} / \mathrm{Cl}^{-}$高达数十到数百, $\mathrm{K}^{+} / \mathrm{Cl}^{-}$ 也在 1 以上. 如在 TDS 最小的加曲水体中, 其比例分别为 132 和 48 . 所以海盐对该流域地表水离子组成 的影响可以忽略. 由于缺乏该区降水化学组分资料, 选择同属藏南、与本区有相同水汽来源 ${ }^{[19]}$ 的拉萨多 年降水化学组分与本区地表水对比 (表 2, 图 3). 拉萨降水化学组成与普莫雍错河流水一样, 优势离子都是 $\mathrm{Ca}^{2+}$ 和 $\mathrm{HCO}_{3}^{-}$, 说明降雨的水化学主要受当地土壤性质的影响 ${ }^{[20]}$. 然而与河流水相比, 拉萨降水中 $\mathrm{Na}^{+}$和 $\mathrm{K}^{+}$比例和 $\mathrm{Cl}^{-}$比例增大, 尤其是 $\mathrm{Cl}^{-}$. 以与加曲 (JQ1-1)比较为例: $\mathrm{Cl}^{-}$在阴离子中相对含量, 拉萨降水 (7.74\% - 8.36\%) 是加曲( $0.02 \%)$ 的 400 倍左右. 在前者 TDS 是后者的 $1 / 4$ 的前提下, $\mathrm{Cl}^{-}$的绝对含量, 前者 
$(21.49-21.55 \mu \mathrm{mol} / \mathrm{L})$ 是后者 $(0.242 \mu \mathrm{mol} / \mathrm{L})$ 的 90 倍左右. 说明两个问题: 相比较地表水而言, 降水还是受到 海盐的较大影响; 两者的巨大差异表明降水对本区地表水离子影响不大. 如果水中 $\mathrm{Na}^{+} / \mathrm{Cl}^{-}$比例为 1 , 可能 有溶解性岩盐或者蒸发盐的直接影响 ${ }^{[18]}$. 在本流域 $\mathrm{Na}^{+} / \mathrm{Cl}^{-}$高值同样排除了这种可能.

表 2 各条人湖河流及拉萨降水的离子组成(\%)和 TDS(mg/L)

(Lhasa87-88 和 Lhasa98-00 分别代表拉萨 1987-1988 年 14 个降水样和 1998-2000 年 15 个降水样*)

Tab.2 Ion composition (equiv.\%) and TDS ( $\mathrm{mg} / \mathrm{L})$ of inflow rivers and precipitation of Lhasa (Lhasa87-88 and Lhasa98-00 stand for 14 precipitation samples of in Lhasa 1987-1988 and 15 precipitation samples in Lhasa 1998-2000)

\begin{tabular}{ccccccccc}
\hline 样点 & $\mathrm{TDS}$ & $\mathrm{Ca}^{2+} / \mathrm{TZ}^{+}$ & $\mathrm{Mg}^{2+} / \mathrm{TZ}^{+}\left(\mathrm{Ca}^{2+}+\mathrm{Mg}^{2+}\right) / \mathrm{TZ}^{+} \mathrm{HCO}_{3}^{-} / \mathrm{TZ}^{-}$ & $\mathrm{Cl}^{-} / \mathrm{TZ}^{-}$ & $\mathrm{SO}_{4}{ }^{2-} / \mathrm{TZ}^{-}\left(\mathrm{Na}^{+}+\mathrm{K}^{+}\right) / \mathrm{TZ}^{+}$ \\
\hline JQZW1-1 & 312.10 & 64.12 & 32.29 & 96.41 & 93.33 & 0.01 & 6.64 & 3.13 \\
JQZW2-1 & 307.15 & 65.05 & 30.96 & 96.01 & 93.53 & 0.01 & 6.45 & 3.54 \\
JQ1-1 & 54.22 & 73.43 & 22.60 & 96.03 & 97.39 & 0.02 & 2.53 & 3.97 \\
JQH1-1 & 547.70 & 22.00 & 56.37 & 78.37 & 93.28 & 0.08 & 6.61 & 21.13 \\
JQH1-2 & 543.30 & 22.11 & 56.35 & 78.46 & 93.13 & 0.08 & 6.76 & 21.05 \\
KQ1-1 & 270.31 & 71.65 & 20.80 & 92.44 & 93.33 & 0.01 & 6.64 & 7.16 \\
XSW1-1 & 280.52 & 64.09 & 31.47 & 95.56 & 94.41 & 0.02 & 5.54 & 4.00 \\
XSW2-1 & 143.33 & 67.46 & 30.61 & 98.07 & 95.49 & 0.01 & 4.50 & 1.93 \\
XSW3-1 & 121.74 & 79.83 & 16.34 & 96.17 & 97.87 & 0.02 & 2.10 & 3.60 \\
DQBYW1-1 & 667.61 & 48.71 & 49.00 & 97.72 & 92.71 & 0.07 & 7.21 & 1.97 \\
RDHW1-1 & 184.62 & 59.98 & 37.08 & 97.06 & 94.82 & 0.05 & 5.12 & 2.94 \\
RDHW1-2 & 174.67 & 60.49 & 36.55 & 97.04 & 94.63 & 0.05 & 5.32 & 2.96 \\
Lhasa87-88 & 14.01 & 57.43 & 7.20 & 64.64 & 90.69 & 7.74 & 0.76 & 29.26 \\
Lhasa98-00 & 13.19 & 83.24 & 4.92 & 88.16 & 86.44 & 8.36 & 2.37 & 8.19 \\
\hline
\end{tabular}

* 由文献[20]整理.
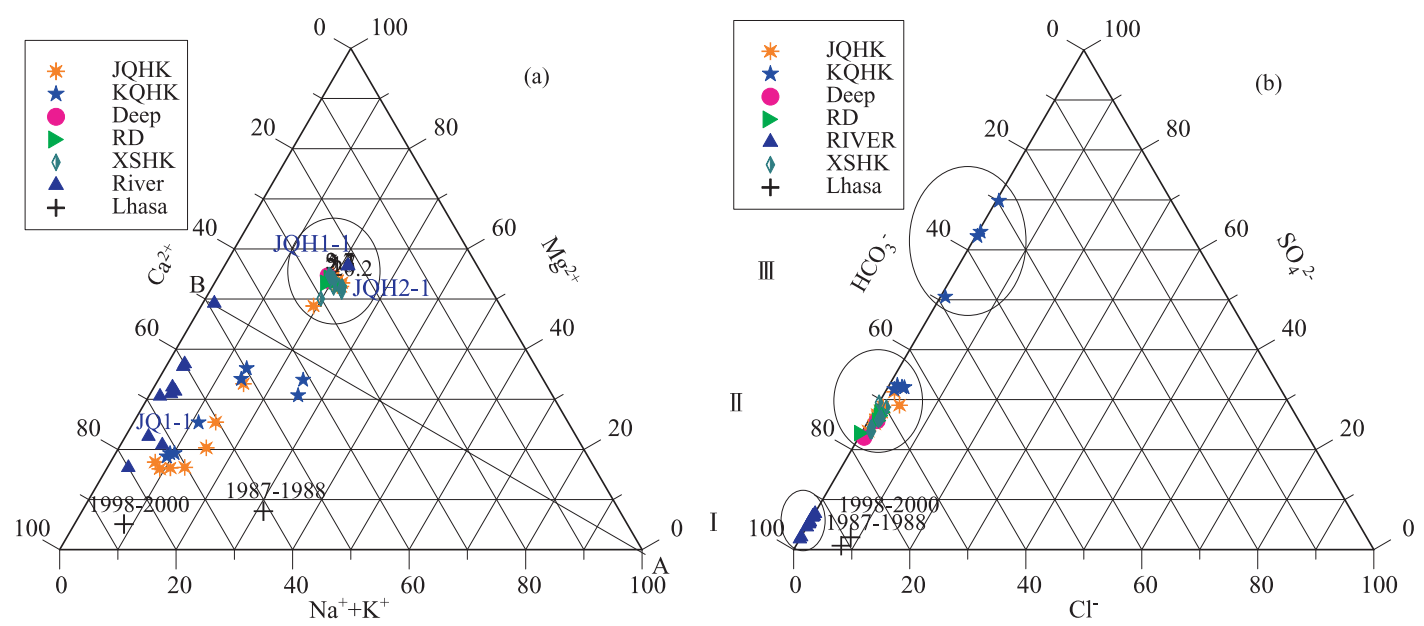

图 3 普莫雍错离子当量浓度组成三角图 (a)阳离子组成( $\mathrm{AB}$ 线: $\mathrm{Ca}^{2+} / \mathrm{Mg}^{2+}=1$ ); (b)阴离子组成

Fig. 3 Ternary plots showing the relative abundances (in equivalent units)

(a): main cations including $\mathrm{Ca}^{2+}, \mathrm{Mg}^{2+}$ and $\left(\mathrm{Na}^{+}+\mathrm{K}^{+}\right)$; (b): main anions including $\mathrm{HCO}_{3}^{-}, \mathrm{SO}_{4}{ }^{2-}$ and $\mathrm{Cl}^{-}$of Lake Pumayum Co (Line AB: $\mathrm{Ca}^{2+} / \mathrm{Mg}^{2+}=1$ ) 
为分析岩石风化对流域水化学组成的影响, 对该流域水样离子按当量浓度分别作三角图(图 3). 就阳 离子三角图来说(图 3a), 各组分点分布在图的左侧, $\mathrm{Ca}^{2+}$ 和 $\mathrm{Mg}^{2+}$ 是阳离子中的主要组成部分, 这两类离子 主要来源于碳酸盐和(或)蒸发盐(如石膏)的风化, 碱土金属的硅酸盐也能提供 $\mathrm{Ca}^{2+}$ 和 $\mathrm{Mg}^{2+}$. 湖泊水和河 流水在该图上的分布同样出现较大差异. 相对于湖泊水, 河流样组分点更靠近 $\mathrm{Ca}^{2+}$ 坐标轴, 即河水中 $\mathrm{Na}^{+}$和 $\mathrm{K}^{+}$相对含量低于湖泊水, $\mathrm{Ca}^{2+}$ 和 $\mathrm{Mg}^{2+}$ 在总阳离子中占绝对优势(表 2, 除了前文介绍的西部冲积扇两条 小河外, 各占 $60 \% 、 30 \%$ 以上, 合占 $90 \%$ 以上).

湖水离子含有更多的 $\mathrm{Mg}^{2+}$ 和 $\mathrm{Na}^{+}, \mathrm{Ca}^{2+}$ 比例有所减少. 在封闭湖盆中, 即使白云岩风化的 $\mathrm{Mg}^{2+}$ 与 $\mathrm{Ca}^{2+}$ 全部进入湖泊, 其摩尔比值至多是 $1^{[18]}$ (见(2)式). 本研究中阳离子三角图中圆圈(高于 $\mathrm{AB}$ 线)内湖水 $\mathrm{Mg}^{2+}$ 与 $\mathrm{Ca}^{2+}$ 已经高于 1 ; 而对河流来说, 除东部小河在 $\mathrm{AB}\left(\mathrm{Ca}^{2+} / \mathrm{Ma}^{2+}=1\right)$ 线上和西部两小溪流在 $\mathrm{AB}$ 线以上外, 其他河流组分点都分布在 $\mathrm{AB}$ 线以下, 说明多数河流阳离子中 $\mathrm{Ca}^{2+}$ 为优势离子. 造成这种差别的原因可 能与湖泊本身的沉积过程有关. 由于强烈蒸发, 湖水中 $\mathrm{Ca}^{2+}$ 析出沉积到沉积物中, 造成 $\mathrm{Ca}^{2+}$ 比例减少, $\mathrm{Mg}^{2+}$ 比例相对升高. 湖水中 $\mathrm{Na}^{+}$和 $\mathrm{K}^{+}$占到 $20 \%$ 左右. $\mathrm{Na}^{+} 、 \mathrm{~K}^{+}$一般来自火成岩或者变质岩, 如钠长石、正 长石和云母等硅酸盐矿物, 这两种离子在湖泊中的高比例同样是与湖水的蒸发浓缩有关.

从阴离子三角图上(图 3b)可以看出, 所有水样组分点紧贴 $\mathrm{HCO}_{3}$ 轴分布, 说明 $\mathrm{Cl}^{-}$含量微乎其微. I 区 为河流样组分点, 分布在 $\mathrm{HCO}_{3}{ }^{-}$高值端, 显示 $\mathrm{HCO}_{3}{ }^{-}$在阴离子组成中占绝对优势地位, $\mathrm{SO}_{4}{ }^{2-}$ 只占 $2 \%$ 到 $7 \%$ (表 2). II 区为荣多河口、加曲河口、湖区中部以及加曲河口和孔曲河口的较深水区(水深大于 $1 \mathrm{~m}$ )的表 层水样品(Deep). 该区 $\mathrm{SO}_{4}{ }^{2-}$ 约占 $20 \%$ 到 $35 \%, \mathrm{HCO}_{3}{ }^{-}$的减少可能与前面推测的湖泊蒸发导致的 $\mathrm{HCO}_{3}{ }^{-}$转化 为 $\mathrm{CO}_{3}{ }^{2-}$ 沉积到底泥中有关. III 区是孔曲河口的表层水样(深度小于 $1 \mathrm{~m}$ ), 该区 $\mathrm{SO}_{4}{ }^{2-}$ 约占 $50 \%-70 \%$.

一般认为, $\mathrm{HCO}_{3}^{-}$由消耗空气土壤中 $\mathrm{CO}_{2}$ 的硅酸盐非全等风化或者溶解在碳酸中的碳酸盐全等风化 提供 ${ }^{[17]}$. $\mathrm{SO}_{4}{ }^{2-}$ 则由蒸发盐的溶解或(和)黄铁矿的氧化风化提供 ${ }^{[21]}$. 碳酸盐风化是 $\mathrm{Mg}^{2+}$ 和 $\mathrm{Ca}^{2+}$ 的主要来源 之一, 其主要反应式:

$$
\begin{aligned}
& \mathrm{CaCO}_{3} \text { (方解石) }+\mathrm{H}_{2} \mathrm{CO}_{3}=\mathrm{Ca}^{2+}+2 \mathrm{HCO}_{3}^{-} \\
& \mathrm{CaMg}\left(\mathrm{CO}_{3}\right)_{2} \text { (白云石) }+2 \mathrm{H}_{2} \mathrm{CO}_{3}=\mathrm{Ca}^{2+}+\mathrm{Mg}^{2+}+4 \mathrm{HCO}_{3}{ }^{-}
\end{aligned}
$$

可以推导出摩尔比 $\left(\mathrm{Ca}^{2+}+\mathrm{Mg}^{2+}\right) / \mathrm{HCO}_{3}{ }^{-}=0.5$ 或者 $\mathrm{Ca}^{2+} / \mathrm{HCO}_{3}{ }^{-}=0.5^{[18]}$. 普莫雍错人湖河流的 $\left(\mathrm{Ca}^{2+}+\mathrm{Mg}^{2+}\right)$ $/ \mathrm{HCO}_{3}{ }^{-}$比例在 0.5 左右(即当量浓度比为 1 左右)(表 3), 说明影响该地区河流水化学离子的主要过程是碳 酸盐的风化. 在不是以碱土金属的硅酸盐为主的地质背景下 ${ }^{[11]}$, 当量浓度比 $\left(\mathrm{Ca}^{2+}+\mathrm{Mg}^{2+}\right) / \mathrm{TZ}^{+}$为大于 0.9 的高值和 $\left(\mathrm{Ca}^{2+}+\mathrm{Mg}^{2+}\right) / \mathrm{HCO}_{3}{ }^{-}$为 1 左右说明碳酸盐的风化是水中溶解离子的主要来源 ${ }^{[22-25]}$. 另外, 该区河 水离子 $\left(\mathrm{Ca}^{2+}+\mathrm{Mg}^{2+}\right) /\left(\mathrm{Na}^{+}+\mathrm{K}^{+}\right)=2-25$, 这与上地壳硅酸盐中的比例 $1^{[26]}$ 相差太大，因此硅酸盐风化对本区 水化学性质影响很小. 由于 $\mathrm{Ca}^{2+}$ 和 $\mathrm{Mg}^{2+}$ 与 $\mathrm{HCO}_{3}{ }^{-}$的当量浓度比为 1 左右, 如果河水中的 $\mathrm{Ca}^{2+}$ 和 $\mathrm{Mg}^{2+}$ 全部 来自碳酸盐风化, 则来自硫酸盐风化的 $\mathrm{Ca}^{2+}$ 和 $\mathrm{Mg}^{2+}$ 比例较小, 因此河水中的 $\mathrm{SO}_{4}{ }^{2-}$ 也不是石亳的溶解贡献, 结合沉积物中 $\mathrm{Fe}$ 的含量在 $40 \mathrm{~g} / \mathrm{kg}$ 以上, 是沉积物中的第三大元素(不包括硅), 推断 $\mathrm{SO}_{4}{ }^{2-}$ 应该主要来源于 黄铁矿的氧化风化.

表 3 普莫雍错人湖河流摩尔比 $\left(\mathrm{Ca}^{2+}+\mathrm{Mg}^{2+}\right) / \mathrm{HCO}_{3}{ }^{-}$和 $\mathrm{Ca}^{2+} / \mathrm{HCO}_{3}{ }^{-}$

Tab.3 Mol ratio $\left(\mathrm{Ca}^{2+}+\mathrm{Mg}^{2+}\right) / \mathrm{HCO}_{3}{ }^{-}$and $\mathrm{Ca}^{2+} / \mathrm{HCO}_{3}{ }^{-}$of inflow river of Lake Pumayum Co

\begin{tabular}{ccccccccccccc}
\hline \multirow{2}{*}{ 样点 } & JQZW & JQZW & JQ & JQH & JQH & KQ & XSW & XSW & XSW & DQBYW & RDHW & \multicolumn{2}{c}{ RDHW } \\
& $1-1$ & $2-1$ & $1-1$ & $1-1$ & $1-2$ & $1-1$ & $1-1$ & $2-1$ & $3-1$ & $1-1$ & $1-1$ & $1-2$ \\
\hline$\left(\mathrm{Ca}^{2+}+\mathrm{Mg}^{2+}\right) / \mathrm{HCO}_{3}^{-}$ & 0.52 & 0.51 & 0.49 & 0.42 & 0.42 & 0.50 & 0.51 & 0.51 & 0.49 & 0.53 & 0.51 & 0.51 \\
$\mathrm{Ca}^{2+} / \mathrm{HCO}_{3}^{-}$ & 0.34 & 0.35 & 0.38 & 0.12 & 0.12 & 0.38 & 0.34 & 0.35 & 0.41 & 0.26 & 0.32 & 0.32 \\
\hline
\end{tabular}

黄铁矿 $\left(\mathrm{FeS}_{2}\right)$ 在氧化带内(浅水区)化学风化反应方程式:

$$
4 \mathrm{FeS}_{2}+15 \mathrm{O}_{2}+8 \mathrm{H}_{2} \mathrm{O}=2 \mathrm{Fe}_{2} \mathrm{O}_{3}+8 \mathrm{H}_{2} \mathrm{SO}_{4}
$$

风化的二价铁被氧化为三价铁, 又由于该湖湖水 $\mathrm{pH}$ 为 8-10, 属弱碱性环境, 能够形成 $\mathrm{Fe}(\mathrm{OH})_{3}$ 沉淀, 故沉积物中 $\mathrm{Fe}$ 含量高, 而湖水中 $\mathrm{Fe}$ 含量很低. 阴离子三角图 III 区是孔曲河口的紧邻北岸的浅水区. $\mathrm{SO}_{4}{ }^{2-}$ 
离子高值可能是因为该区北岸黄铁矿较多.

根据以上分析, 本区河水主要阳离子 $\mathrm{Ca}^{2+}$ 和 $\mathrm{Mg}^{2+}$ 和主要阴离子 $\mathrm{HCO}_{3}^{-}$受碳酸盐(方解石和白云石)风 化影响最大, 硅酸盐风化影响较小而 $\mathrm{SO}_{4}{ }^{2-}$ 与黄铁矿氧化风化有关. 由于本区地层少见岩盐或蒸发盐 ${ }^{[11]}$, 溶解风化对本区影响不明显. 除了以上相关过程外, 湖水的化学性质还受湖泊自身的碳酸盐沉积过程影 响, 导致去 $\mathrm{Ca}^{2+}$ 和 $\mathrm{HCO}_{3}{ }^{-}$的作用发生.

\section{4 表层湖水化学性质及其氧同位素的空间分布}

3.4 .1 表层湖水化学性质空间分布 对加曲河口(JQHK)、孔曲河口(KQHK)、荣多河口(RDHK)、下索河口 (XSHK)垂直等深线不同位置的表层湖水化学性质进行对比分析(图 4a, b, c, d, e). 结果显示加曲河口和孔 曲河口的湖水化学成分空间变化比较明显. 在加曲河口剖面, 水化学离子和 TDS 随与河口距离增大而变 大. 从 3 号样(水深 $1.6 \mathrm{~m}$ )开始增加, 到 5 号样(水深 $2.0 \mathrm{~m}$ )开始显著增加. 但是, 由于不同水化学离子的增 幅不同, 导致普莫雍错湖水化学性质与补给河水具有差异: $\mathrm{Mg}^{2+}$ 和 $\mathrm{Na}^{+}$超越 $\mathrm{Ca}^{2+}$ 成为阳离子中第一和第二 优势成分. 到 7 号样(水深 $2.8 \mathrm{~m}$ ), 各个水化学离子含量和 TDS 开始保持稳定. 对于孔曲河口, 从 4 号样开 始, 水化学离子就与湖水成分接近一致. 在荣多河口与下索河口, 水化学离子含量基本与距河口远近无 关. 以上河口区的水化学离子空间分布变化表明, 流量大的加曲对湖泊水化学离子分布具有更广泛的影 响，而其他流量较小的河流河口区与湖区内部具有很小的变化，说明湖区水化学离子成分与补给河流具 有密切的联系, 但湖泊本身的作用又能够改造补给河流的水化学状况, 使得整个湖泊的水化学条件趋于
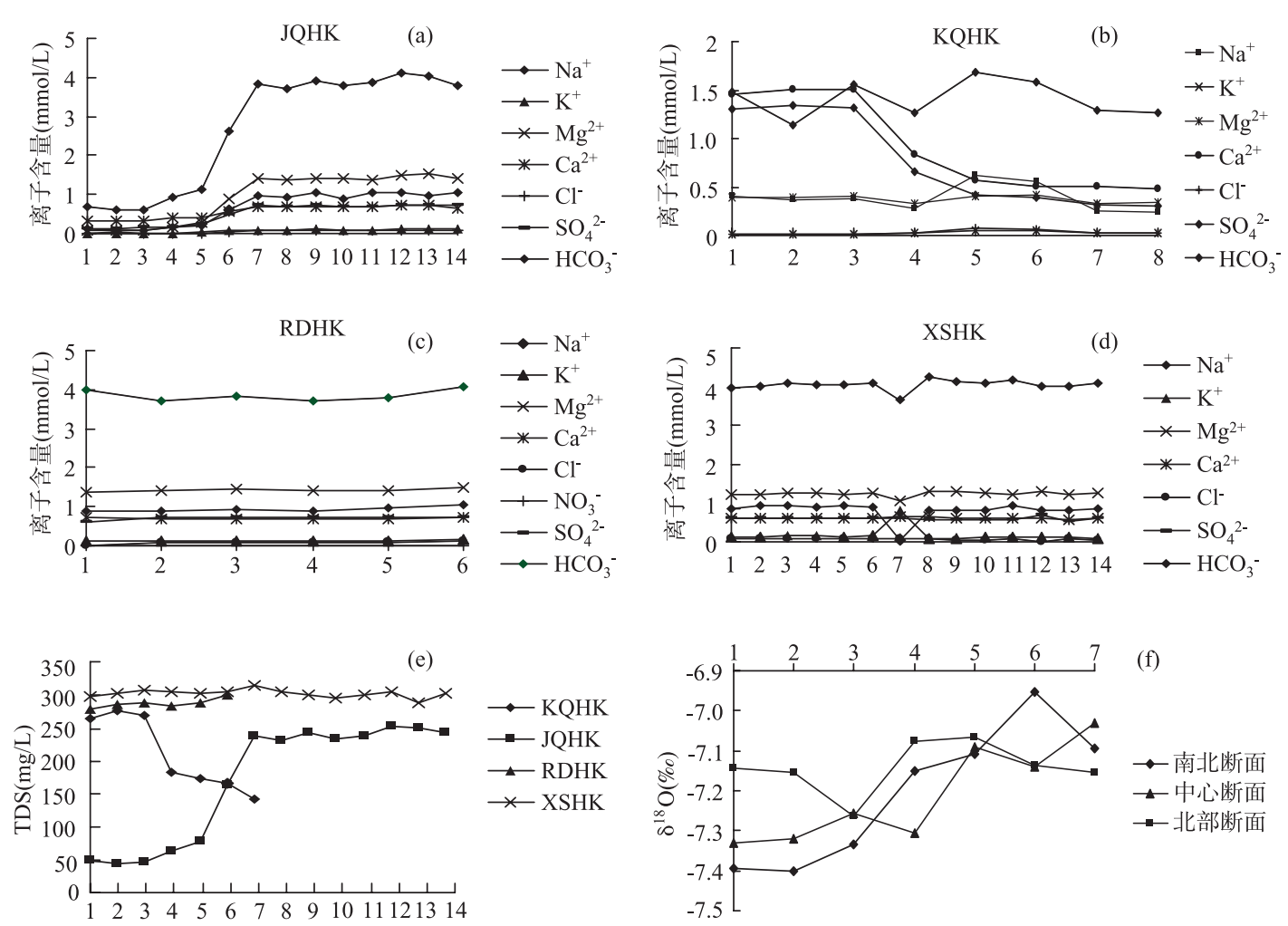

图 4 普莫雍错水参数的空间分布(横坐标为样点号; a, b, c, d 分别是湖泊的 4 条测线; $\mathrm{e}$ 是 TDS 在 4 个湖区空间变化(见图 1); f 是氧同位素在 3 条测线的空间变化(见图 1))

Fig.4 Spatial distribution of hydro-parameter of Lake Pumayum Co. X Axis is sample numbers; Plot a, b, c and $\mathrm{d}$ show the four survey lines in the lake; Plot e indicates the TDS variation in four parts of Lake Pumayum Co (see Fig.1); Plot f shows spatial variations of oxygen isotope according to the 3 survey line (see Fig.1) 
一致. 由 58 个湖泊表层水电导率数据(图 1)和实测离子换算成 TDS 浓度插值得到的普莫雍错 TDS 等值线 图(图略)也可以看出西侧湖区 TDS 非常明显的空间差异，而其他湖区则比较等值线稀疏，大多在 $290 \mathrm{mg} / \mathrm{L}$ 左右. 尽管其他河口水域 TDS 空间差异相对较小, 然而也存在从河口到内部增大的微弱趋势. 1 号岛(最大的岛)以东是高值区，达到 $294 \mathrm{mg} / \mathrm{L}$. 相对南部湖区，没有河流注人的北部湖区 TDS 也偏高. 3.4 .2 表层湖水氧同位素的空间分布 普莫雍错流域地表径流主要是冰雪融水补给河流. 在海洋性冰川区 域, 从冰雪向冰雪融水再到补给河流河水转化过程中, $\delta^{18} \mathrm{O}$ 垂直变化梯度逐渐增大. 这与河水在流动中受 到再蒸发作用导致的分馏有关 ${ }^{[27]}$. 湖水的同位素组成并不等同于原始补给水的同位素值. 由于蒸发作用 的影响，都在一定程度上相对富集重同位素. 在干旱的湖泊中，强烈的蒸发将导致重同位素的连续富集， 随着离内流点的距离增加，它将与盐度成平行增长 ${ }^{[28]}$. 因此湖水的氧同位素值的分布能够反映不同补给 源对湖泊影响。

该区雨季降水 $\delta^{18} \mathrm{O}$ 为 $-20 \%$ 左右 ${ }^{[19]}$, 最大补给河流加曲河水为 $-16.4 \%$, 湖泊表层水样(图 4f, 断面见 图 1)增至-7\%o左右. 湖水与河水 $\delta^{18} \mathrm{O}$ 大的差异, 说明了湖面蒸发导致的重氧同位素的相对富集. 尽管湖 泊内部表层湖水氧同位素差别相对较小, 但是通过三条断面比较也可以看出明显的空间差异: 湖中心东 西比较结果显示, 从西往东普莫雍错湖水氧同位素比值逐渐增大 (从- $7.33 \%$ 增至 $-7.03 \%$ ); 北部湖区剖面 氧同位素比值有波动变化; 下索湾口处到北岸自南往北逐渐增大 $($ 从 $-7.41 \%$ 至 $-7.09 \%$ ). 这与 TDS 在湖泊 内的分布相似.

\section{4 结论与讨论}

从当量浓度来看, 普莫雍错湖水的主要阳离子组成是 $\mathrm{Mg}^{2+} 、 \mathrm{Ca}^{2+} 、 \mathrm{Na}^{+} 、 \mathrm{~K}^{+} 、 \mathrm{Sr}^{2+}$, 阴离子的主要组 成是 $\mathrm{HCO}_{3}{ }^{-} 、 \mathrm{SO}_{4}{ }^{2-} 、 \mathrm{Cl}^{-}$; 流域内人湖河流的主要阳离子组成是 $\mathrm{Ca}^{2+} 、 \mathrm{Mg}^{2+} 、 \mathrm{Na}^{+} 、 \mathrm{Sr}^{2+} 、 \mathrm{~K}^{+}$, 阴离子组成 顺序与湖水相同, 不过 $\mathrm{SO}_{4}^{2}$-更少, $\mathrm{HCO}_{3}$ - 占绝对优势.

Gibbs 图说明控制本区水化学成分的主要过程是岩石的风化. 三角图和离子比值分析不仅揭示水离 子主要来源于碳酸盐、黄铁矿和硅酸盐风化，而且揭示了各条河流之间、河流与湖泊之间水化学性质的 差异. 河口区水化学组成的差异与补给河流的流量具有密切联系. 流量较大的加曲和孔曲, 其河口处水 化学离子的组成空间差异大, 而其他河流人湖口处与深水区水离子分布在 Gibbs 图、阳离子三角图和阴 离子三角图上基本为同一区域, 表明这些河流对普莫雍错影响不明显. 湖泊水化学空间差异分析进一步 说明发源于南部冰川的河流对湖泊的水化学性质的影响. 从河口区到湖心, 湖水的 TDS 有增加的趋势, 氧同位素比值也有类似空间差异.

除了 TDS 的明显差异之外, 湖水与补给河水的另外一个显著差异是其 $\mathrm{Ca}^{2+}$ 当量浓度的变化. 湖泊西 侧加曲河口处, 受加曲河水影响, 阳离子组成中 $\mathrm{Ca}^{2+}$ 是最大优势离子. 远离河口到水深 $2 \mathrm{~m}$ 的水域, TDS 增加到一个稳定值, 阳离子中 $\mathrm{Mg}^{2+}$ 成为最大优势阳离子, $\mathrm{Na}^{+}$和 $\mathrm{K}^{+}$也有所增加. 对于一个处于半干旱区 的半封闭湖泊来说, 湖水 TDS 要比补给河流高是因为湖水的蒸发浓缩, 降水、河流水和湖水的 $\delta^{18} \mathrm{O}$ 的比 较也证明了这一点. 在蒸发浓缩的过程中, 由于钻盐的在水中溶解度小于镁盐 ${ }^{[6]}, \mathrm{Ca}^{2+}$ 以碳酸钻的形式沉 积下来, 从而在水中出现 $\mathrm{Ca}^{2+}$ 的减少现象. 在喜马拉雅山南坡 Mansar 湖中, Al-Mikhlafi 等 ${ }^{[29]}$ 报道干季与 湿季 $\mathrm{Ca}^{2+}$ 的差异是因为干季碳酸盐的沉积. 恒河一雅鲁藏布江(Brahmaputra)水系研究 ${ }^{[22,30]}$ 也表明, 在枯 水期，由于蒸发强盛，低地(low land)河流碳酸盐沉降，去除了部分 $\mathrm{Ca}^{2+}$, 导致了 $\mathrm{Mg}^{2+} / \mathrm{Ca}^{2+}$ 比值是丰水期 的 2 倍. 这与本研究研究角度不同, 但是得到了相似的结论. 因此影响湖泊水化学离子组成的因素除了 碳酸盐、硅酸盐和黄铁矿的风化外, $\mathrm{Ca}^{2+}$ 的沉积过程也是个重要因素. 然而在一个较为稳定的盐度背景下, 碳酸盐的沉淀还受生物、水温等因素的影响, 因而明确该湖碳酸盐含量在古湖泊研究中的环境意义还需 进一步的研究.

致谢：在论文写作过程中，与中国科学院青藏高原所冯金良博士、张强弓同学进行了有益的讨论，高 晶同学在氧同位素数据方面给予帮助, 实验室曲冬梅女士在分析试验中给予了帮助, 在此一并表示 感谢. 


\section{5 参考文献}

[1] 朱立平, 鞠建廷, 王君波等. 湖芯沉积物揭示的末次冰消开始时期普莫雍错湖区环境变化. 第四纪研究, 2006, 26(5): 772-780.

[2] 王苏民, 窦鸿身. 中国湖泊志. 北京: 科学出版社, 1998: 21-22, 83, 405 .

[3] John DL. Study and interpretation of the chemical characteristics of natural water. Alexandria, VA: Department of the Interior, U.S. Geological Survey, US Water-Supply Paper, 1985: 2254.

[4] Stallard RF, Edmond JM. Geochemistry of Amazon. 2 The influence of geology and weathering environment on the dissolved load. J Geophys Res, 1983, 88: 9671-9688.

[5] 陈敬安, 万国江, 黄荣贵. 程海近代气候的化学记录. 海洋地质与第四纪地质, 2000, 20(1): 39-42.

[6] 沈照理. 水文地球化学基础. 北京: 地质出版社, 1986: 70-71, 77-78, 83.

[7] 朱立平, 陈 玲, 李炳元等. 西昆仑山南红山湖沉积反映的过去150年湖区环境变化. 中国科学(D辑), 2001, 31(7): 601-607.

[8] 朱立平, 王君波, 陈 玲等. 藏南沉错湖泊沉积多指标揭示的2万年来环境变化. 地理学报, 2004, 59(4): 514-524.

[9] 吴艳宏, 王苏民, 夏威岗等. 青藏高原中部0.2ka来的环境变化. 中国科学(D辑), 2001, 31(增刊): 264-268.

[10] 顾兆炎, 刘嘉鹿, 袁宝印等. 湖相自生沉积作用与环境——兼论西藏色林错沉积物记录. 第四纪研究, 1994, (2): 162-174.

[11] 西藏自治区地质矿产局. 西藏自治区区域地质志. 北京: 地质出版社, 1993: 142.

[12] 李炳元, 王富葆, 张青松等. 西藏第四纪地质. 北京: 科学出版社, 1983: 15.

[13] 关志华, 陈传友, 区裕雄等. 西藏河流与湖泊. 北京: 科学出版社, 1984: 141.

[14] Gibbs RJ. Mechanism controlling world water chemistry. Science, 1970, 170: 1088-1090.

[15] 赵华标, 姚檀栋, 徐柏青. 慕土塔格卡尔塔马克冰川作用区的水文与水化学特征. 冰川冻土, 2006, 28(2): 269-275.

[16] 盛文坤, 王宁练, 蒲健辰. 唐古拉山冬克玛底冰川作用区的水化学特征. 冰川冻土, 1996, 18(3): 235-243.

[17] Berner EK, Berner RA. The global water cycle. Prentice-Hall, Englewood Cliffs, 1987: 397.

[18] Zhang J, Huang WW, Letolle R et al. Major element chemistry of the Huanghe (Yellow River), China: weathering processes and chemical fluxes. $J$ Hydrol, 1995, 168: 173-203.

[19] 尹常亮，田立德，余武生等. 羊卓雍错流域降水中稳定氧同位素变化特征. 冰川冻土, 2006, 28(6): 919-924.

[20] 章 典, 师长兴, 假 拉. 青藏高原降水化学研究. 环境科学学报, 2004, 24(3): 555-557.

[21] 李学礼. 水文地球化学. 北京: 原子能出版社, 1988: 19.

[22] Sarin MM, Krishnaswami S, Dilli K et al. Major ion chemistry of the Ganga-Brahmaputra river system: weathering processes and flux to the Bay of Bengal. Geochim Cosmochim Acta, 1989, 53: 997-1009.

[23] Pandey SK, Singh AK, Hasnain SI. Weathering and geochemical processes controlling solute acquisition in Ganga Headwater-Bhagirathi River, Garhwal Himalaya, India. Aquatic Geochemistry, 1999, 5: 357-379.

[24] Singh AK, Hasnain SI. Environmental geochemistry of Damodar River basin—east coast of India. Environmental Geology, 1999, 37: 124-136

[25] Abhay KS, Hasnain SI. Aspects of weathering and solute acquisition processes controlling chemistry of sub-Alpine proglacial streams of Garhwal Himalaya, India. Hydrol Process, 2002, 16: 835-849.

[26] Taylor SR, McLennan SM. The continental crust: its composition and evolution. Oxford: Blackwell, 1985.

[27] 庞进喜, 何元庆, 卢爱刚等. 玉龙雪山冰川稳定同位素分馏冬夏对比. 地理学报, 2006, 61(5): 501-509.

[28] 尹 观. 同位素水文地球化学. 成都: 成都科技大学出版社, 1988: 146-147.

[29] AL-Mikhlafi AS, Das BK, Kaur P. Water chemistry of Mansar Lake (India): an indication of source area weathering and seasonal variability. Environ Geol, 2003, 44(6): 645-653.

[30] Handra BK. Geochemistry of the Ganga River Water. Ind Geohydroi, 1972, (2): 71-78. 